\title{
Synchronized ovulation for first insemination improves reproductive performance and reduces cost per pregnancy in dairy heifers
}

\author{
T. V. Silva, ${ }^{*} \dagger$ F. S. Lima, $¥$ W. W. Thatcher, ${ }^{*} \dagger$ and J. E. P. Santos ${ }^{*} \dagger^{1}$ \\ *Department of Animal Sciences, and \\ †D. H. Barron Reproductive and Perinatal Biology Research Program, University of Florida, Gainesville 32611 \\ ‡Department of Veterinary Clinical Medicine, University of Illinois, Urbana 61802
}

\begin{abstract}
The objectives were to evaluate the effects of synchronizing estrus and ovulation to implement a timed artificial insemination (AI) at first insemination on reproductive performance and cost per pregnancy in dairy heifers. Six hundred eleven Holsteins heifers at approximately $400 \mathrm{~d}$ of age from 3 farms were enrolled in the study. Six days before moving to the breeding pens, heifers were allocated randomly to AI after detected estrus from study d 0 to $84(\mathrm{CON}, \mathrm{n}=306)$, or to timed AI for first AI followed by detected estrus for the remainder of the 84-d study (TAI, $\mathrm{n}=305$ ). Heifers receiving TAI were enrolled in the 5-d timed AI protocol on study $\mathrm{d}-6(\mathrm{~d}-6, \mathrm{GnRH}$ and a progesterone insert; $\mathrm{d}-1, \mathrm{PGF}_{2 \alpha}$ and insert removal; $\mathrm{d} 0$, $\mathrm{PGF}_{2 \alpha} ; \mathrm{d} 2, \mathrm{GnRH}+\mathrm{AI}$ ), and they were allowed to be bred the day before scheduled timed AI if detected in estrus. Starting on study d 0, estrus was detected daily. Heifers in estrus were inseminated on the same morning as detected estrus. Control heifers not inseminated by study $\mathrm{d} 7$ received $\mathrm{PGF}_{2 \alpha}$ and this treatment was repeated every 2 wk until AI. The study lasted $84 \mathrm{~d}$ to allow a period of breeding equivalent to four 21-d estrous cycles. A herd budget accounting for inputs for both treatments was created to determine the cost per pregnancy. Sensitivity analysis compared economic differences between the 2 treatments under different input scenarios when detection of estrus after the first AI varied from 50 to $80 \%$. Interval to first AI was $8 \mathrm{~d}$ shorter for TAI than for CON. Pregnancy at first AI did not differ between treatments $(\mathrm{CON}=58.3 \mathrm{vs}$. TAI $=62.8 \%)$. In contrast, TAI increased pregnancy per AI (P/AI) compared with CON in heifers inseminated with sex-sorted semen $(\mathrm{CON}=31.6$ vs. $\mathrm{TAI}=54.8 \%)$. The 21-d cycle insemination rate was greater for TAI (91.4\%) than for CON $(82.4 \%)$, even when evaluated
\end{abstract}

Received April 13, 2015.

Accepted June 25, 2015

${ }^{1}$ Corresponding author: jepsantos@ufl.edu after the first $21 \mathrm{~d}$ in the study $(\mathrm{CON}=68.2 \mathrm{vs}$. TAI $=$ $77.1 \%$ ). The increased insemination rate improved the 21-d cycle pregnancy rate from $47.9 \%$ in CON to $57.2 \%$ in TAI heifers. In fact, the hazard of pregnancy was $60 \%$ greater for TAI than CON. The increased pregnancy rate in TAI reduced the median days to pregnancy by $12 \mathrm{~d}(\mathrm{CON}=2.0$ vs. TAI $=14.0)$ and increased the proportion of pregnant heifers by 6.3 percentage points by study d $84(\mathrm{CON}=85.2$ vs. TAI $=91.5 \%)$. The cost per pregnancy was $\$ 17.00$ less for TAI than CON. The sensitivity analysis indicated that TAI was economically more advantageous to produce a pregnancy compared with CON. Only when insemination rate after the first $21 \mathrm{~d}$ of breeding was very high and $\mathrm{P} / \mathrm{AI}$ was relatively low did the cost per pregnancy become similar for the 2 treatments. Collectively, inseminating all heifers within $2 \mathrm{~d}$ of breeding with the 5 -d timed AI protocol maintains $\mathrm{P} / \mathrm{AI}$, improves pregnancy rate, and reduces cost per pregnancy compared with insemination after detected estrus.

Key words: 5-d timed artificial insemination, economics of reproduction, dairy heifer, pregnancy

\section{INTRODUCTION}

The use of timed AI programs is low in dairy heifers compared with in lactating dairy cows (NAHMS, 2009). Programs to synchronize ovulation of dairy heifers based on $\mathrm{GnRH}$ and $\mathrm{PGF}_{2 \alpha}$ historically have resulted in low pregnancy per AI (P/AI) compared with insemination performed after detected estrus (Schmitt et al., 1996; Pursley et al., 1997b; Rivera et al., 2004). The inability to achieve P/AI following timed AI comparable with that of insemination after detected estrus is likely caused by the inadequacy of some hormonal protocols to properly synchronize follicle growth and ovulation in heifers. The reduced $\mathrm{P} / \mathrm{AI}$ for timed AI programs based on GnRH and $\mathrm{PGF}_{2 \alpha}$ and the perception by dairy producers that heifers become pregnant easily without intervention likely explain the limited use of ovulation synchronization protocols for management of reproduction in heifers. 
Recently, the 5-d timed AI protocol developed by Rabaglino et al. (2010) and extensively evaluated by Lima et al. $(2011,2013)$ resulted in P/AI above $59 \%$ for first insemination and above $55 \%$ for second insemination in Holstein and crossbred dairy heifers. Such results are similar to those obtained when AI is performed after detection of spontaneous or $\mathrm{PGF}_{2 \alpha}$-induced estrus in dairy heifers (Kuhn et al., 2006). The reproductive outcomes reported by Lima et al. (2013) suggest that synchronization of ovulation using the 5-d timed AI protocol is an attractive alternative for dairy producers to increase the rate of insemination and potentially reduce time to pregnancy and, consequently, feed costs associated with raising heifers. It is unclear, however, if the incorporation of timed AI in breeding programs of dairy heifers improves reproductive performance beyond what is observed with insemination on estrus. It is unknown whether synchronized ovulation with timed $\mathrm{AI}$ can result in $\mathrm{P} / \mathrm{AI}$ equal to that observed when dairy heifers are inseminated on estrus. Rabaglino et al. (2010) showed no difference in P/AI during a resynchronized insemination between the 5 -d timed AI protocol and heifers that were inseminated following spontaneous return to estrus. Nevertheless, the study of Rabaglino et al. (2010) was not designed to assess differences between insemination after detected estrus or timed AI. Lima et al. (2013) showed that it is possible to achieve high $\mathrm{P} / \mathrm{AI}$ in dairy heifers using the 5 -d timed AI protocol to synchronize ovulation for insemination at fixed time.

The major cost in replacement programs in dairy farms is feed, accounting for almost $45 \%$ of the total costs in Dutch farms (Mohd Nor et al., 2012) and up to $64 \%$ in US dairy farms (Gabler et al., 2000). When pregnancy is delayed, the costs of feed increase because heifers calve at an older age, and each additional day of rearing represents additional 12 to $14 \mathrm{~kg}$ of DM intake. Therefore, improving pregnancy rate to reduce age at first calving becomes attractive primarily because of the reduction in feed costs.

The hypotheses of the current study were that synchronizing ovulation using the 5-d timed AI protocol for the first insemination would result in similar P/ AI to that of control heifers inseminated after detected estrus, but increase insemination rate and reduce time to pregnancy. A second hypothesis was that increasing the rate of insemination and pregnancy with timed AI would present economic benefits by reducing the cost per pregnancy compared with heifers inseminated only after detected estrus. Therefore, the objectives of the present study were to evaluate $\mathrm{P} / \mathrm{AI}$, pregnancy rate, and the economics of producing a pregnancy in dairy heifers when subjected to synchronized ovulation for first insemination followed by detection of estrus compared with insemination only after detected estrus.

\section{MATERIALS AND METHODS}

The University of Florida Institute of Food and Agricultural Sciences Animal Research Committee approved all procedures in this study.

\section{Heifers, Housing, and Feeding}

Six hundred twelve nulliparous nonpregnant Holstein heifers from 3 dairy farms in central California were enrolled in the study: 149 in farm 1, 126 in farm 2, and 337 in farm 3. Heifers were enrolled as 10 weekly cohorts ranging from 31 to 121 heifers each. Heifers were moved to the breeding pens once weekly when they were at least $384 \mathrm{~d}$ of age, and the average ages at enrollment $( \pm \mathrm{SD})$ were $400.9 \pm 11.8 \mathrm{~d}$ in farm $1,400.0$ $\pm 10.3 \mathrm{~d}$ in farm 2 , and $400.9 \pm 8 \mathrm{~d}$ in farm 3. Heifers were housed in dry lots with self-locking stanchions along the feed lane. Heifers were enrolled in the months of April, May, and June 2014, and the last heifer had the final pregnancy diagnosis performed in November 2014. Within farm, heifers were fed a TMR once daily between 0700 and $0830 \mathrm{~h}$ that met or exceeded the nutritional requirements of Holstein heifers weighing 360 $\mathrm{kg}$ and gaining $0.9 \mathrm{~kg} / \mathrm{d}$ (NRC, 2001). In all 3 farms, the diets fed to heifers contained wheat silage, sorghum silage, alfalfa hay, straw, corn gluten feed, cottonseed meal, citrus pulp, and a mineral and vitamin premix containing monensin sodium.

\section{Experimental Design and Treatments}

The experiment was a randomized complete block design. Prepared randomization forms were designed for each farm with blocks of 2 heifers each such that both treatments were represented in random sequence. Allocation of heifers to treatments within block was performed randomly based on sequence of identification of heifers in the pens on the day of enrollment in each farm. The day when the heifer was moved to the breeding pen was considered the day of enrollment and called study d 0 .

Six days before moving to the breeding pens (study d -6 ), heifers were blocked by sequence of identification in the pen and, within block, randomly allocated to 1 of 2 treatments. Treatments were implemented to start insemination on study $\mathrm{d} 0$. Treatments were AI after detected estrus resulting from spontaneous or $\mathrm{PGF}_{2 \alpha^{-}}$ induced estrus from study d 0 to 84 (control, CON, n $=306$ ), or timed AI for first insemination, followed by 
detection of estrus for the remainder of the 84-d study (TAI, $\mathrm{n}=306$ ). Heifers receiving TAI were enrolled in the 5-d timed AI protocol (Lima et al., 2013) on study d -6 . The protocol included an i.m. injection of 100 $\mu \mathrm{g}$ of $\mathrm{GnRH}(50 \mu \mathrm{g} / \mathrm{mL}$ gonadorelin diacetate tetrahydrate; OvaCyst, Bayer HealthCare Animal Health, Whippany, NJ) and vaginal insertion of a previously used and autoclaved (Cerri et al., 2009) controlled internal drug release (CIDR) that originally contained $1.38 \mathrm{~g}$ of progesterone (Eazi-Breed CIDR Cattle Insert, Zoetis, Florham Park, NJ). On study d -1 , the CIDR was removed and heifers received an i.m. injection of 25 $\mathrm{mg}$ of $\mathrm{PGF}_{2 \alpha}(5 \mathrm{mg} / \mathrm{mL}$ of dinoprost as tromethamine salt; ProstaMate, Bayer HealthCare Animal Health). On study d 0 , heifers were moved to the breeding pens and received another injection of $\mathrm{PGF}_{2 \alpha}$. Timed AI was performed on d 2 concurrent with the final injection of GnRH (Figure 1). Any TAI heifer that showed estrus on study d 1, the day before scheduled timed AI, was inseminated and the final injection of $\mathrm{GnRH}$ administered concurrent with AI. Therefore, the TAI treatment was a combination of insemination after detected estrus on study d 1 and timed AI on study d 2 .

Starting on study d 0, all heifers were moved to the breeding pens and had their tailheads painted daily with chalk (All Weather Paintstik, LA-CO Industries Inc., Elk Grove Village, IL). Removal of the chalk was interpreted as an indication of estrus. Heifers were evaluated daily in the morning immediately after feeding, and any heifer showing signs of estrus such as accepting mount or with rubbed tailheads was inseminated on the same morning. Control heifers that did not show signs of estrus within $7 \mathrm{~d}$ of moving to the breeding pen received an injection of $\mathrm{PGF}_{2 \alpha}$. Treatment with $\mathrm{PGF}_{2 \alpha}$ was repeated every 2 wk in CON heifers until first AI. In farm 1, heifers were inseminated by 2 technicians using semen from 6 sires, 4 of which were sex-sorted and 2 were conventional semen. In farm 2 , heifers were inseminated by 2 technicians using semen from 7 sires, 2 of which were sex-sorted and the other 5 were conventional. In farm 3 , heifers were inseminated by 5 technicians using semen from 8 sires, 6 of which were only conventional and 2 were conventional and sex-sorted. Because some sires were common among farms, 14 sires in total were used in the study. Allocation of individual sires and type of semen was random across treatments. A total of 130 heifers were inseminated with sex-sorted semen for the first AI, $57 \mathrm{CON}$ (19.2\% of AI) and 73 TAI (23.9\% of AI). After the first AI, only conventional semen was used for the subsequent inseminations. The study lasted $84 \mathrm{~d}$ to allow a period of breeding with duration equivalent to four 21-d estrous cycles.

\section{Pregnancy Diagnoses and Evaluation of P/AI and Pregnancy Loss at First Al}

Pregnancy was evaluated $32 \mathrm{~d}$ after the timed AI and at $32 \pm 3 \mathrm{~d}$ after insemination in CON heifers.

\section{Control}

\section{Detection of estrus and $\mathrm{AI}$}

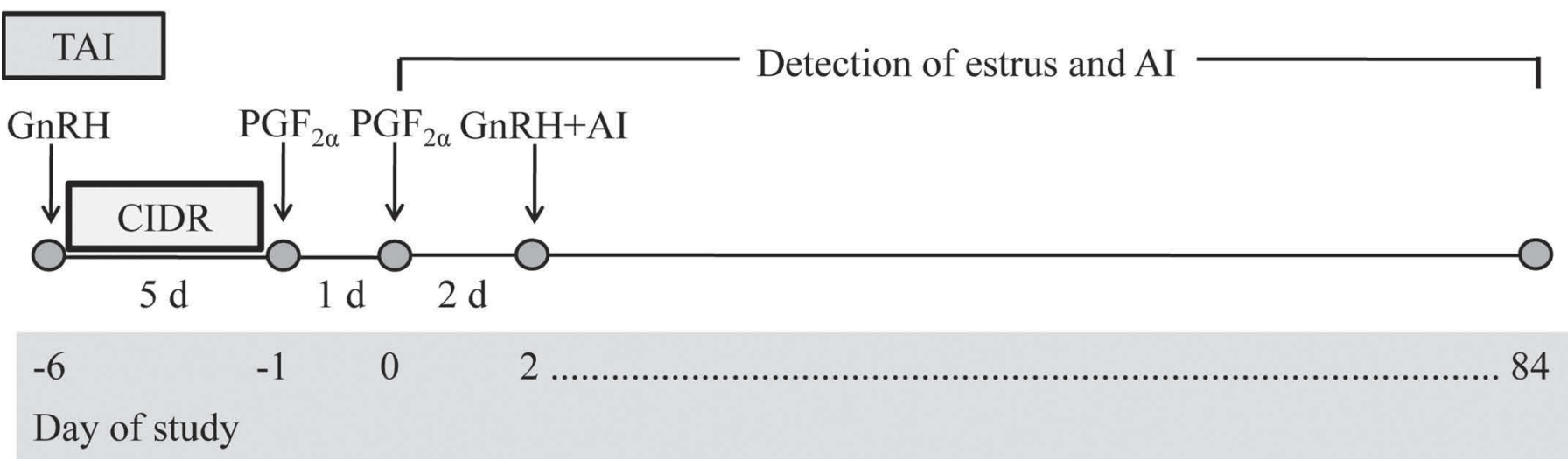

Figure 1. Diagram of activities in the experiment. Heifers were assigned to AI after being detected in estrus (control) from d 0 to 84 or timed AI (TAI) using the 5-d timed AI protocol depicted in the figure for first insemination followed by detection of estrus for the remainder of the 84-d study. CIDR = previously used controlled internal drug-release containing progesterone; GnRH $=$ injection of $100 \mu \mathrm{g}$ of gonadorelin diacetate tetrahydrate; $\mathrm{PGF}_{2 \alpha}=$ injection of $25 \mathrm{mg}$ of dinoprost as tromethamine salt. 
Pregnancy diagnosis was performed by transrectal ultrasonography using a portable ultrasound equipped with a $7.5-\mathrm{MHz}$ transrectal linear transducer (EasiScan, BCF Technology, Rochester, MN). The presence of an embryo with a heartbeat was the criterion used to determine pregnancy. Heifers diagnosed pregnant were re-examined by transrectal ultrasonography $28 \mathrm{~d}$ later at $60 \mathrm{~d}$ of gestation to reconfirm pregnancy and identify pregnancy loss. Heifers that returned to estrus after the first AI and before a pregnancy diagnosis were considered nonpregnant. Pregnancy per AI was calculated by dividing the number of heifers diagnosed pregnant at 32 or $60 \mathrm{~d}$ after $\mathrm{AI}$ by the number of heifers that received AI. Proportion of heifers that had pregnancy loss was calculated as the number of heifers that lost a pregnancy between 32 and $60 \mathrm{~d}$ of gestation divided by the number diagnosed pregnant on d 32 after the first AI.

\section{Pregnancy per Al at Repeat Al and Interval to Pregnancy}

After the first AI, all repeat inseminations for CON and TAI heifers were performed after detected estrus. Heifers that returned to estrus after any insemination were considered as nonpregnant. Pregnancy was evaluated by transrectal ultrasonography on d $60 \pm 3$ after all repeat inseminations. For interval to pregnancy, heifers were considered pregnant based on the diagnosis of pregnancy on d 60 after AI.

\section{Economic Analysis}

A partial budget was developed to calculate the economic differences between the reproductive programs used for CON and TAI using specific inputs for each heifer in each farm. The structure of the economic analysis included expenses with hormones for synchronization of estrus or ovulation; labor associated with hormone administration and detection of estrus and AI; semen and AI supplies; costs of pregnancy diagnosis; and feed costs. The values described herein were based on measurements on all 3 farms, and average values are represented for each input.

The costs of hormones for synchronization of estrus and ovulation were based on current market prices and averaged $\$ 2.00 /$ dose for $\mathrm{GnRH}$ and $\mathrm{PGF}_{2 \alpha}$. The cost of the CIDR insert was based on the market price of $\$ 8.00$ but considering 2 uses per insert (Cerri et al., 2009) and the cost of cleaning and autoclaving, which resulted in a cost of $\$ 4.12$ for the CIDR insert. An additional $\$ 0.02$ was added to each injection to cover costs of syringes and needles based on usage in each farm. All labor was based on a wage of $\$ 10 / \mathrm{h}$. Treatments per person were evaluated in each farm to estimate the cost of labor for hormone administration, detection of estrus, and insemination. A person was able to perform one of the following tasks per hour: administer injections to 120 heifers, apply 40 CIDR, or remove 80 inserts. Therefore, the calculated cost to implement the TAI protocol was $\$ 12.87$. The number of $\mathrm{PGF}_{2 \alpha}$ treatments was considered for CON heifers. Detection of estrus was based on daily application of chalk and a person was able to handle 120 heifers per hour. The costs associated with AI included $\$ 6.00$ for conventional semen and supplies or $\$ 18.00$ for sex-sorted semen and supplies. A person was able to inseminate 30 heifers per hour. Pregnancy diagnosis was calculated at $\$ 2.00$ per diagnosis. Heifers that were diagnosed pregnant on $\mathrm{d} 32$ received a second diagnosis.

Each extra day to pregnancy after the day of entry into the breeding group results in additional feed costs because of a later age at calving. For heifers that became pregnant, the additional feed cost was based on the average value of the TMR fed to late-gestation heifers, which was $\$ 0.17 / \mathrm{kg}$ of DM, and the estimated DMI of $13.0 \mathrm{~kg} / \mathrm{d}$ for each day of delay in calving for a pregnant Holstein heifer that weighs approximately 580 $\mathrm{kg}$ at $23 \mathrm{mo}$ of age and consumes approximately $2.25 \%$ of her BW in DM daily to support $0.9 \mathrm{~kg}$ of BW gain (NRC, 2001). For heifers that remained nonpregnant throughout the 84-d study, the additional cost was based on the average value of the TMR fed to breeding heifers, which was $\$ 0.20 / \mathrm{kg}$ of DM and an estimated DMI of $9.0 \mathrm{~kg} / \mathrm{d}$ for each day in the study for breeding age Holstein heifer that weighs approximately $400 \mathrm{~kg}$ at $14 \mathrm{mo}$ of age and consumes approximately $2.25 \%$ of her BW in DM daily to support $0.9 \mathrm{~kg}$ of $\mathrm{BW}$ gain (NRC, 2001).

The final cost was the summation of each input of the partial budget, which was calculated per heifer enrolled in the study and per pregnancy obtained at the end of the 84 -d breeding period.

\section{Sensitivity Analysis}

Five scenarios were created to investigate the effects of variations in feed cost, labor wage, hormonal treatment cost, semen price, and P/AI. Each scenario was evaluated under different insemination rates following the first 21-d period. Insemination rate in the first 21-d of breeding was the observed study values of $100 \%$ for TAI and $93.5 \%$ for CON. In the subsequent 21-d periods (study d 22 to 84 ), detection of estrus was assumed to vary from 50 to $80 \%$ in 10-percentage-unit increments, and they were equal in both treatments. Therefore, in 
each of the scenarios, only one variable (feed cost, labor wage, hormonal treatment cost, semen price, or P/AI) under distinct insemination rates was evaluated, and the remaining inputs were kept constant based on the results observed in the study.

The initial calculations used the baseline values observed for insemination rate and $\mathrm{P} / \mathrm{AI}$ observed in the study to generate the pregnancy rate for each $21-\mathrm{d}$ period and the respective mean days to pregnancy for each treatment. The first scenario evaluated the effect of varying feed cost for each extra day to pregnancy after the entry into the breeding group. It was assumed that each day would result in additional feeding of a late-gestation heifer that consumes $13 \mathrm{~kg}$ of DM (NRC, 2001 ) and with ration costs at $\$ 0.15, \$ 0.18$, or $\$ 0.21 /$ $\mathrm{kg}$ of DM. In the second scenario, the cost of hormonal treatments varied from $\$ 10.00, \$ 13.00$, or $\$ 16.00$ to implement the TAI, or $\$ 1.67, \$ 2.17$, or $\$ 2.67$ to administer $\mathrm{PGF}_{2 \alpha}$ to $\mathrm{CON}$ heifers. All TAI heifers received one timed $\mathrm{AI}$ and $64 \%$ of the $\mathrm{CON}$ heifers received $\mathrm{PGF}_{2 \alpha}$. In the third scenario, we assumed that only conventional semen would be used and the price of semen and insemination supplies would be $\$ 4.00, \$ 7.00$, or $\$ 10.00$. In the fourth set of scenarios, labor wage varied from $\$ 8.00, \$ 11.00$, or $\$ 14.00 / \mathrm{h}$. In the last scenario, the $\mathrm{P} /$ AI was altered to result in $90 \%, 80 \%$, or $70 \%$ of that observed for TAI and CON to evaluate the economic impact of the 2 treatments under different heifer fertility scenarios.

All sensitivity analyses are presented as difference in costs observed for CON minus those of TAI to obtain a pregnancy during the 84-d breeding period.

\section{Statistical Analyses}

The sample size was calculated based on the anticipated rate of pregnancy for CON heifers and the expected increase of $30 \%$ for TAI. The number of experimental units was sufficient to detect a difference (2-sided test; $\alpha=0.05 ; \beta=0.20$ ) in rate of pregnancy when the daily rate of pregnancy for CON heifers is $2.0 \%$ (e.g., 42 pregnancies out of 100 eligible CON heifers in $21 \mathrm{~d}$ of breeding), the relative risk of pregnancy for TAI is 1.30 ( $30 \%$ greater than that of CON), and the study duration is $84 \mathrm{~d}$ (Machin et al., 2008). Under those assumptions, 270 heifers per treatment, or a total of 540, were needed. Because of potential attrition, 612 heifers were enrolled.

The statistical models for analyses of data included the fixed effects of treatment (CON vs. TAI), farm $(1,2,3)$, interaction between treatment and farm, and the random effect of block. Additional covariates such as technician nested within farm and semen type (conventional vs. sexed) were used when univariable analysis indicated statistical effect $(P<0.10)$. Binary responses were analyzed by logistic regression using the GLIMMIX procedure of SAS version 9.3 (SAS/STAT, SAS Institute Inc., Cary, NC). Adjusted odds ratio and respective $95 \%$ CI were calculated. Intervals to first $\mathrm{AI}$ and to pregnancy were analyzed by the Cox's proportional hazard model using the PHREG procedure of SAS. Adjusted hazard ratio and respective 95\% CI were calculated. The time variables used in the models were the intervals in days between study d 0 and the day of AI or pregnancy. Heifers that did not receive any AI or those that remained nonpregnant or were sold or moved to a bull pen before study d 84 were censored. The median and mean days to pregnancy were obtained from the LIFETEST procedure of SAS.

Costs associated with the respective treatments were analyzed using the MIXED procedure of SAS. The models included the fixed effects of treatment, farm, interaction between treatment and farm, and the random effect of block. The Kenward-Roger method was used to calculate the approximate denominator degrees of freedom for the $\mathrm{F}$ tests in the mixed models. Differences with $P \leq 0.05$ were considered significant and $0.05<P \leq 0.10$ were considered tendencies.

\section{RESULTS}

Six hundred twelve nulliparous nonpregnant Holstein heifers were enrolled in the study, but one TAI heifer was removed because she was diagnosed as having a single uterine horn. Therefore, 611 heifers were included in the statistical analyses.

\section{Reproduction at First Al}

The median days from introduction into the breeding pens to first AI were reduced by $8 \mathrm{~d}(P<0.001)$ for TAI than for CON heifers (Table 1). Approximately $26.9 \%$ of the TAI heifers ( 82 of 305 heifers) were inseminated on study d 1 because they showed estrus the day before the scheduled day of timed insemination. The remaining 223 TAI heifers were inseminated on study d 2, which was the day of timed AI. On the day of timed AI, $66.4 \%$ of the TAI heifers showed signs of estrus based on removal of tail chalk, resulting in $75.4 \%$ of the TAI heifers displaying estrus $(230 / 305)$. The $\mathrm{P} / \mathrm{AI}$ was numerically smaller but not statistically different $(P=$ 0.13 ) for heifers not showing signs of estrus compared with those showing signs of estrus in the TAI treatment (no estrus $=58.1$ vs. estrus $=67.8 \%$ ). In addition, the $\mathrm{P} / \mathrm{AI}$ for TAI heifers inseminated on study $\mathrm{d} 1$ or at the 
Table 1. Effect of treatment on fertility responses of dairy heifers at first AI

\begin{tabular}{|c|c|c|c|c|}
\hline Item & \multicolumn{2}{|c|}{ Treatment $^{1}$} & $\operatorname{AOR}^{2}(95 \% \mathrm{CI})$ & $P$-value \\
\hline \multicolumn{5}{|l|}{ Days to first AI } \\
\hline Mean \pm SEM & $10.4 \pm 0.4$ & $1.7 \pm 0.1$ & - & - \\
\hline Heifers inseminated, \% & $97.1(297 / 306)$ & $100(305 / 305)$ & - & - \\
\hline \multicolumn{5}{|l|}{ Pregnant first $\mathrm{AI}^{3}$} \\
\hline \multicolumn{5}{|c|}{ Pregnant d 60 according to semen type ${ }^{4}$} \\
\hline Conventional, \% (no./no.) & $64.6(155 / 240)$ & $65.4(151 / 231)$ & $1.04(0.71-1.51)$ & 0.86 \\
\hline Sex-sorted, \% (no./no.) & $31.6(18 / 57)$ & $54.8(40 / 73)$ & $2.63(1.26-5.46)$ & 0.01 \\
\hline
\end{tabular}

${ }^{1} \mathrm{CON}=\mathrm{AI}$ after detected in spontaneous estrus or estrus induced by $\mathrm{PGF}_{2 \alpha}$ from d 0 to 84 of the study; TAI = timed AI using the 5-d timed AI protocol for the first AI followed by detection of estrus for the remainder of the 84-d study.

${ }^{2} \mathrm{AOR}=$ adjusted odds ratio; $\mathrm{CON}$ is the reference for comparison.

${ }^{3}$ Nine CON heifers left the study before being detected in estrus and inseminated. One TAI heifer was diagnosed with a single uterine horn and removed from the study and another was moved to a bull pen the day after TAI.

${ }^{4}$ Interaction between treatment and type of semen $(P=0.02)$ was observed for pregnancy per AI on d 32 and 60 after insemination.

scheduled timed AI on study d 2 did not differ $(P=$ $0.85)$ and were, respectively, 64.6 and $65.8 \%$.

Of the 306 CON heifers, 139 were inseminated without receiving any $\mathrm{PGF}_{2 \alpha}$, whereas $167(54.6 \%)$ received at least one dose of $\mathrm{PGF}_{2 \alpha}$ before the first AI. Seventeen heifers received 2 or more doses of $\mathrm{PGF}_{2 \alpha}$ before first AI. Control heifers received $\mathrm{PGF}_{2 \alpha}$ because they were not detected in estrus within the first week of insemination, and their first AI occurred $9 \mathrm{~d}$ later $(P<0.001)$ than that of CON heifers not treated with $\mathrm{PGF}_{2 \alpha}(5.2$ vs. $14.4 \pm 0.4 \mathrm{~d})$. A total of 193 doses $(0.64 /$ heifer $)$ of $\mathrm{PGF}_{2 \alpha}$ were administered to $\mathrm{CON}$ heifers before first AI. Fourteen CIDR inserts were lost $(4.6 \%)$ before the day of removal. All TAI heifers were inseminated, whereas $9 \mathrm{CON}$ heifers left the study before being detected in estrus and inseminated.

Treatment did not affect $\mathrm{P} / \mathrm{AI}$ at first $\mathrm{AI}$ and it averaged $63.9 \%$ on d 32 after AI and $60.6 \%$ on d 60 of gestation (Table 1). Pregnancy loss between gestation d 32 and 60 did not differ between treatments and averaged $5.2 \%$. Farm affected $(P<0.001) \mathrm{P} / \mathrm{AI}$ and it was less in farm 1 that used mostly sexed semen for first insemination (farm $1=50.0 \%$ vs. farm $2=64.0 \%$ vs. farm $3=70.5 \%$ ). No interaction between treatment and farm was detected for $\mathrm{P} / \mathrm{AI}$ or pregnancy loss. Insemination technician did not affect $\mathrm{P} / \mathrm{AI}$ on $\mathrm{d} 32$ or 60 after the first AI or pregnancy loss. Use of sexsorted semen reduced $(P<0.01) \mathrm{P} / \mathrm{AI}$ (conventional $=68.6$ vs. sexed $=46.9 \%)$. An interaction $(P=0.02)$ between treatment and semen type was detected for $\mathrm{P} /$ AI because heifers inseminated with sex-sorted semen had greater $(P<0.01) \mathrm{P} / \mathrm{AI}$ on $\mathrm{d} 32$ and 60 after insemination when receiving TAI compared with $\mathrm{CON}$ (Table 1).

\section{Reproduction After the First Al}

Insemination rate for the 84-d study was greater $(P$ $<0.001$ ) for TAI than for CON heifers (Table 2). Even after the first 21-d cycle, heifers receiving TAI also had greater $(P=0.005)$ insemination rate than $\mathrm{CON}$ heifers. The repeat AI occurred $10 \mathrm{~d}$ earlier $(P<0.001)$ in TAI than CON (Figure 2). Many CON heifers received the second AI only after $30 \mathrm{~d}$ in the study, whereas most of the TAI heifers were re-inseminated within $26 \mathrm{~d}$ in the study. Treatment did not affect $\mathrm{P} / \mathrm{AI}$ at all $\mathrm{AI}$ or the $\mathrm{P} / \mathrm{AI}$ for repeat $\mathrm{AI}$. The $\mathrm{P} / \mathrm{AI}$ for all $\mathrm{AI}$ averaged $56.7 \%$ based on the diagnosis on d 60 after insemination. Because of the increased insemination rate, the 21 -d cycle pregnancy rate was greater $(P=0.008)$ for TAI than for CON heifers. After the first 21-d cycle, pregnancy rate was only numerically greater for TAI than CON heifers. Similar to the 21-d-cycle pregnancy rate, heifers receiving TAI had $60 \%$ greater $(P<0.001)$ hazard of pregnancy (adjusted hazard ratio $=1.60$; $95 \% \mathrm{CI}=1.35$ to 1.89 ) than CON heifers (Table 3 ; Figure 3). This increased rate of pregnancy resulted in a reduction in the median days to pregnancy of 12 d (Table 3) and an additional 6.2 percentage points of pregnancy by study d 84 . Farm influenced the rate of pregnancy, and farm 1 had greater $(P<0.05)$ days to pregnancy and lesser pregnancy rate than farms 2 and 3. Nevertheless, no interaction between treatment and farm was observed for the variables evaluated.

\section{Economic Analysis}

Treatment influenced all variables considered in the cost per heifer enrolled in the experiment. Heifers re- 
Table 2. Effect of treatment on fertility responses of dairy heifers for the 84-d study

\begin{tabular}{|c|c|c|c|c|}
\hline Item & \multicolumn{2}{|c|}{ Treatment $^{1}$} & $\operatorname{AOR}^{2}(95 \% \mathrm{CI})$ & $P$-value \\
\hline \multicolumn{5}{|c|}{ 21-d cycle insemination rate, $\%$ (no./no.) } \\
\hline After first $21-\mathrm{d}$ cycle & $68.2(163 / 239)$ & $77.1(141 / 183)$ & $2.67(1.35-5.26)$ & 0.005 \\
\hline \multicolumn{5}{|c|}{ Pregnancy per AI on d $60, \%$ (no./no.) } \\
\hline All AI & $56.0(261 / 466)$ & $57.4(279 / 486)$ & $1.14(0.86-1.50)$ & 0.37 \\
\hline All 21-d cycles & $47.9(261 / 545)$ & $57.2(279 / 488)$ & $1.47(1.11-1.94)$ & 0.008 \\
\hline After first 21-d cycle & $34.7(83 / 239)$ & $38.8(71 / 183)$ & $1.37(0.88-2.13)$ & 0.17 \\
\hline
\end{tabular}

${ }^{1} \mathrm{CON}=\mathrm{AI}$ after detected in spontaneous estrus or estrus induced by $\mathrm{PGF}_{2 \alpha}$ from d 0 to 84 of the study; TAI = timed AI using the 5-d timed AI protocol for the first AI followed by detection of estrus for the remainder of the 84-d study.

${ }^{2} \mathrm{AOR}=$ adjusted odds ratio; $\mathrm{CON}$ is the reference for comparison.

${ }^{3}$ Pregnancy was based on diagnosis on d 60 after AI.

ceiving TAI had greater $(P<0.05)$ costs associated with hormonal treatment, semen and AI, and pregnancy diagnosis compared with CON heifers (Table 4). However, implementing TAI resulted in reduced $(P<$ $0.05)$ costs with detection of estrus and extra feed to raise the heifers than $\mathrm{CON}$, which resulted in a ten- dency $(P=0.08)$ for a reduction in total cost of $\$ 9.43 /$ heifer when enrolled in the TAI compared with CON (Table 4).

When costs were calculated per pregnancy, then the differential between treatments favored even more the TAI than CON (Table 4). Heifers receiving TAI had

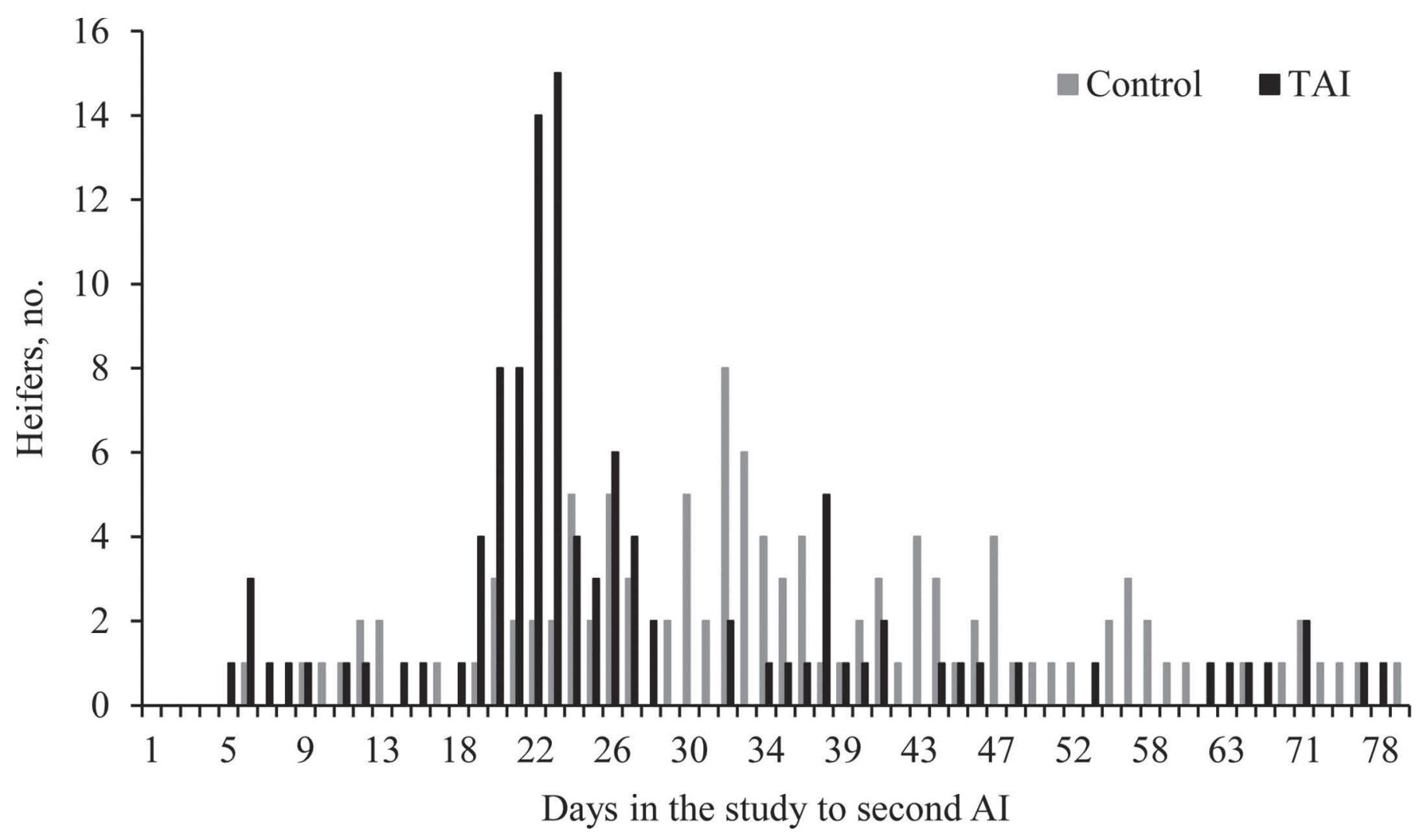

Figure 2. Histogram of days in the study at the second insemination for the 111 control and 107 timed AI (TAI) heifers that received a second AI during the 84 -d breeding period. The mean $( \pm$ SEM $)$ and median days in the study to second AI were, respectively, $36.3 \pm 1.5$ and 33.0 for control, and $26.8 \pm 1.5$ and 23.0 for TAI $(P<0.001)$. 


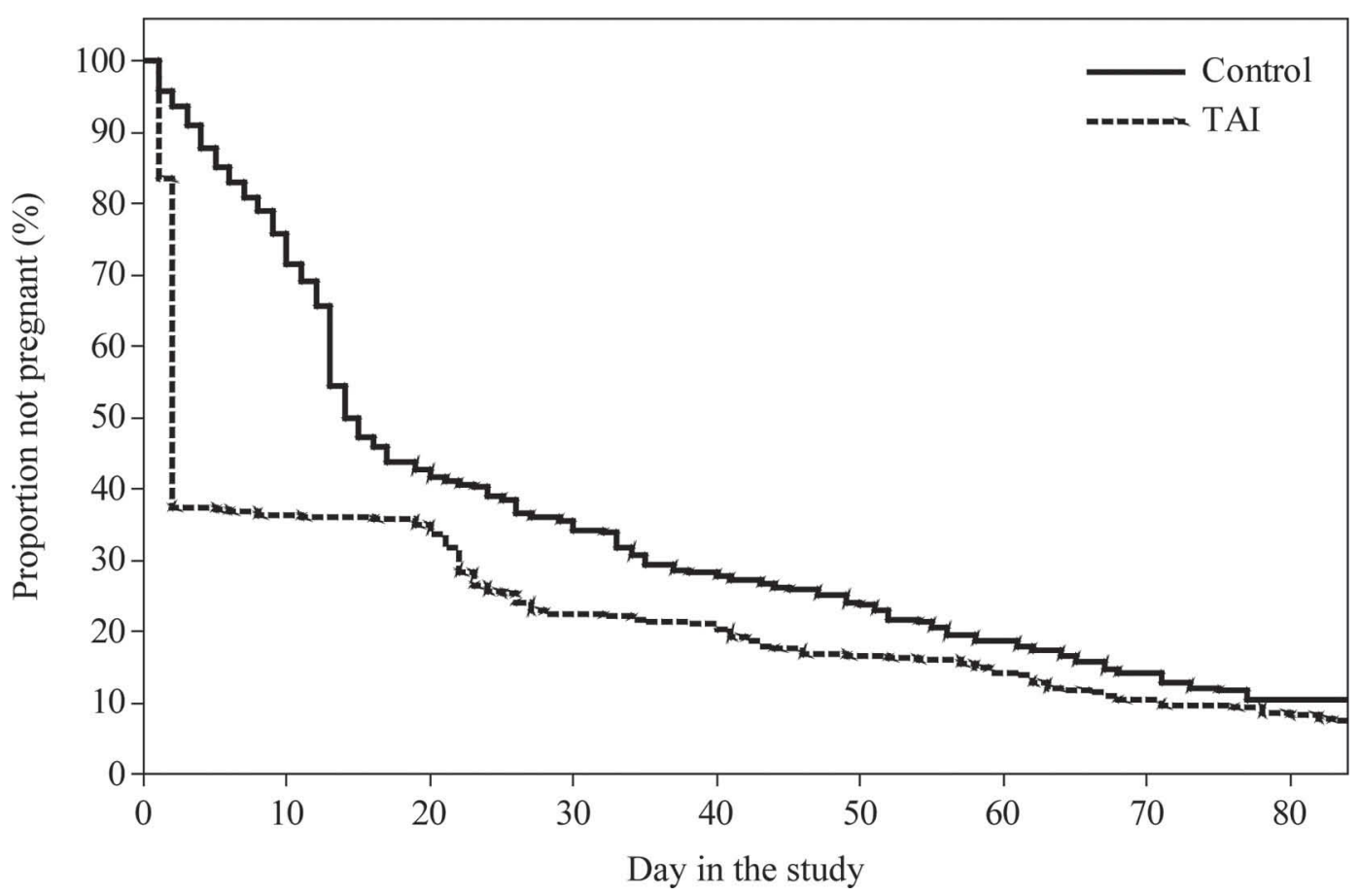

Figure 3. Survival curves for time to pregnancy for heifers assigned to insemination after detected estrus (control) or timed AI (TAI) for first insemination. Control heifers were observed for estrus daily based on removal of tail chalk or mounting activity and if not in estrus received $\mathrm{PGF}_{2 \alpha}$. Heifers in TAI were assigned to the 5 - $\mathrm{d}$ timed AI protocol (d 0 of the protocol, injection of $100 \mu \mathrm{g}$ of GnRH and CIDR; $\mathrm{d} 5$ of the protocol, injection of $25 \mathrm{mg}$ of $\mathrm{PGF}_{2 \alpha}$ and removal of the CIDR; $\mathrm{d} 6$ of the protocol, injection of $25 \mathrm{mg}$ of $\mathrm{PGF}_{2 \alpha}$; 8 of the protocol, injection of $100 \mu \mathrm{g}$ of $\mathrm{GnRH}$ and timed insemination) for first AI followed by detection of estrus thereafter. Effect of treatment $(P<0.001 ;$ adjusted hazard ratio $=1.60 ; 95 \% \mathrm{CI}=1.35$ to 1.89$)$.

greater $(P<0.01)$ cost associated with hormonal treatments than CON to generate a pregnancy, whereas the opposite was observed for costs associated with detection of estrus and additional feed. Costs of semen and pregnancy diagnosis did not differ between treatments when calculated per pregnancy. The calculated cost to generate a pregnancy in TAI was $\$ 17.00$ less $(P<0.01)$ than that for CON (Table 4).

\section{Sensitivity Analysis}

Increments in cost per kilogram of DM increased the economic advantage of TAI over CON to generate a pregnancy (Table 5). The benefit was detected using the observed insemination rates for the study, as well as under distinct insemination rates after the first 21 $\mathrm{d}$ of breeding. It is also clear that as insemination rate

Table 3. Cox's proportional hazard model for time to pregnancy

\begin{tabular}{|c|c|c|c|c|c|}
\hline Item & \multicolumn{2}{|c|}{ Days to pregnancy ${ }^{1}$} & Pregnant, \% (no./no.) & $\mathrm{AHR}^{2}(95 \% \mathrm{CI})$ & $P$-value \\
\hline \multicolumn{6}{|c|}{$\overline{\text { Treatment }^{3}}$} \\
\hline $\mathrm{CON}$ & $14.0(13.0-17.0)$ & $28.9 \pm 1.6$ & $85.3(261 / 306)$ & Reference & - \\
\hline TAI & $2.0(1.0-2.0)$ & $18.9 \pm 1.6$ & $91.5(279 / 305)$ & $1.60(1.35-1.89)$ & 0.001 \\
\hline \multicolumn{6}{|l|}{ Farm } \\
\hline 1 & $22.0(11.0-30.0)$ & $30.4 \pm 2.4$ & $89.2(132 / 148)$ & Reference & - \\
\hline
\end{tabular}

${ }^{1}$ Pregnancy was based on the diagnosis on d 60 after AI.

${ }^{2} \mathrm{AHR}=$ adjusted hazard ratio.

${ }^{3} \mathrm{CON}=\mathrm{AI}$ after detected in spontaneous estrus or estrus induced by $\mathrm{PGF}_{2 \alpha}$ from d 0 to 84 of the study; TAI = timed AI using the 5-d timed AI protocol for the first AI followed by detection of estrus for the remainder of the 84-d study. 
Table 4. Effects of treatment (CON vs. TAI) on costs per heifer or per pregnancy

\begin{tabular}{|c|c|c|c|c|c|}
\hline \multirow[b]{2}{*}{ Item $^{1}$} & \multicolumn{2}{|c|}{ Treatment $^{2}$} & \multirow[b]{2}{*}{ SEM } & \multirow[b]{2}{*}{ Difference $^{3}$} & \multirow[b]{2}{*}{$P$-value } \\
\hline & $\mathrm{CON}$ & TAI & & & \\
\hline \multicolumn{6}{|l|}{ Costs per heifer, US $\$$} \\
\hline Hormonal treatment & 1.31 & 12.87 & 0.06 & -11.56 & $<0.01$ \\
\hline Detection of estrus & 4.57 & 3.92 & 0.10 & 0.65 & $<0.01$ \\
\hline Semen and AI & 13.28 & 14.50 & 0.40 & -1.22 & 0.03 \\
\hline Pregnancy diagnosis & 3.68 & 3.86 & 0.05 & -0.18 & $<0.01$ \\
\hline Extra feed & 62.11 & 40.43 & 3.46 & 21.68 & $<0.01$ \\
\hline Total cost & 85.00 & 75.57 & 3.88 & 9.43 & 0.08 \\
\hline \multicolumn{6}{|l|}{ Cost per pregnancy, US\$ } \\
\hline Hormonal treatment & 1.54 & 14.07 & 0.08 & -12.53 & $<0.01$ \\
\hline Detection of estrus & 5.37 & 4.28 & 0.11 & 1.09 & $<0.01$ \\
\hline Semen and AI & 15.56 & 15.83 & 0.45 & -0.27 & 0.68 \\
\hline Pregnancy diagnosis & 4.31 & 4.22 & 0.05 & 0.09 & 0.22 \\
\hline Extra feed & 72.82 & 44.17 & 3.91 & 28.65 & $<0.01$ \\
\hline Total cost & 99.59 & 82.59 & 4.36 & 17.00 & $<0.01$ \\
\hline \multicolumn{6}{|c|}{$\begin{array}{l}{ }^{1} \text { See Materials and Methods for details on the inputs used. Costs were calculated as per heifer enrolled in eac } \\
\text { treatment and per pregnancy obtained by } 84 \mathrm{~d} \text { of breeding. }\end{array}$} \\
\hline \multicolumn{6}{|c|}{$\begin{array}{l}{ }^{2} \mathrm{CON}=\mathrm{AI} \text { after detected in spontaneous estrus or estrus induced by } \mathrm{PGF}_{2 \alpha} \text { from d } 0 \text { to } 84 \text { of the study; } \mathrm{T} \\
=\text { timed AI using the } 5 \text {-d timed AI protocol for the first AI followed by detection of estrus for the remaind } \\
\text { of the } 84 \text {-d study. }\end{array}$} \\
\hline \multicolumn{6}{|c|}{${ }^{3}$ Calculated as the cost for CON minus the cost for TAI. A positive value denotes higher cost for CON tha } \\
\hline
\end{tabular}

increases, the benefit of TAI over CON is reduced under all feed cost scenarios evaluated. Variations in labor wage had a relatively small effect on the differences between CON and TAI. Using the extremes of wage evaluated, TAI was still economically more advantageous than $\mathrm{CON}$ for the distinct insemination rates evaluated (Table 5). Increments in cost of synchronization reduced the benefit of TAI relative to CON. Nevertheless, when the cost of synchronization was high, $\$ 16.00$ for TAI and $\$ 2.67$ for $\mathrm{PGF}_{2 \alpha}$, TAI remained superior to CON even when insemination rate was set at $80 \%$, approximately $\$ 3.90$ cheaper to generate a pregnancy. The cost of semen and supplies for insemination had a minor effect on the economic differences between treatments. Manipulating the P/AI to have 90 to $70 \%$ of the observed study values showed a distinct pattern of change in economic differences between treatments according to the insemination rates considered. When insemination rate was low (i.e., 50\%), then reducing $\mathrm{P} / \mathrm{AI}$ from 90 to $70 \%$ of the values observed in the study increased the benefit of TAI over CON. On the other hand, as insemination rate increased, to 60 or up to $80 \%$, then reducing $\mathrm{P} / \mathrm{AI}$ decreased the economic benefit of TAI over CON. In fact, when P/AI was only $70 \%$ of those observed in the study, then no economic benefit was detected if insemination rate was $80 \%$.

\section{DISCUSSION}

Inseminating heifers using a combination of AI in estrus and at fixed time using the 5-d timed AI proto- col resulted in similar $\mathrm{P} / \mathrm{AI}$ to that observed in heifers inseminated after detected estrus. Because all TAI heifers were inseminated within the first $2 \mathrm{~d}$ in the study, it increased the rates of insemination and pregnancy, and reduced the interval to pregnancy. The benefits of inseminating all heifers within $2 \mathrm{~d}$ in the study with TAI persisted through the 84-d breeding period and resulted in 6.2 more pregnancies for every 100 breeding heifers compared with CON.

Pursley et al. (1995) was the first to evaluate the Ovsynch protocol to synchronize ovulation in dairy heifers. Those authors showed that ovulation to the initial and final GnRH of the Ovsynch protocol was less in heifers than in lactating cows, and suggested that the protocol was less effective at synchronizing follicle growth and ovulation in heifers compared with lactating cows. In fact, subsequent studies by the same group (Pursley et al., 1997b) and others (Schmitt et al., 1996) showed that the Ovsynch resulted in $\mathrm{P} / \mathrm{AI}$ that was less than that typically observed when heifers are inseminated at detected estrus. Based on work with lactating cows (Pursley et al., 1997a), we anticipated that if a timed AI protocol results in $\mathrm{P} / \mathrm{AI}$ similar to that of insemination at detected estrus, it should then improve the rate of pregnancy. The current study demonstrated that implementation of the 5-d timed AI protocol increased insemination rate throughout the 84-d breeding period compared with CON. The similar P/ $\mathrm{AI}$ at first and subsequent inseminations for $\mathrm{CON}$ and TAI but the greater 21-d cycle insemination rate for TAI increased the hazard of pregnancy by $60 \%$. Indeed, 
the 21-d cycle pregnancy rate increased for TAI and the benefit was mainly attributable to the first $21 \mathrm{~d}$ of breeding.

In most dairy farms in the United States (NAHMS, 2009), dairy heifers are artificially inseminated following detection of estrus. The low adoption of timed AI in dairy heifers is likely the result of anticipated high detection of estrus, which makes reproductive programs based on $\mathrm{PGF}_{2 \alpha}$ attractive. Moreover, the most common protocol for timed AI used in lactating dairy cows, the Ovsynch protocol, is not ideal for use in dairy heifers (Schmitt et al., 1996; Pursley et al., 1997b). The inability of Ovsynch and Cosynch to result in high $\mathrm{P} / \mathrm{AI}$ has been observed even when heifers had the estrous cycle presynchronized with an injection of GnRH 6 (Stevenson et al., 2008a) or 7 d (Rivera et al., 2006) before enrollment in the timed AI protocol. On the other hand, when timed AI for heifers is optimized by including an injection of $\mathrm{GnRH}$ on $\mathrm{d} 0$ and a second dose of $\mathrm{PGF}_{2 \alpha}$ on $\mathrm{d} 6$ of the 5 -d timed AI protocol (Lima et al., 2013), then P/AI are usually similar to that typically reported as standard for the industry
(Kuhn et al., 2006). Indeed, results from the current study showed that $\mathrm{P} / \mathrm{AI}$ in dairy heifers was similar when insemination followed synchronized ovulation with the 5-d timed AI protocol or after detected estrus.

Interestingly, an interaction between treatment and type of semen used was detected because TAI heifers had greater P/AI than CON heifers when insemination was performed with sex-sorted semen. One explanation is that induction of ovulation with the 5 -d timed AI protocol resulted in better-synchronized ovulation with proper timing of ovulation relative to semen deposition. It is known that sexed semen results in reduced $\mathrm{P} / \mathrm{AI}$ compared with insemination using conventional semen (Seidel, 2014). The reduction in $\mathrm{P} / \mathrm{AI}$ is attributed to the fewer sperm cells per inseminating dose and to the damage to sperm caused by the sorting process (Seidel, 2014). It is known that $\mathrm{P} / \mathrm{AI}$ improves as timing of AI and ovulation are optimized (Saacke, 2008) and that sex-sorted sperm cells have a shorter fertilizing viability in the female reproductive tract than spermatozoa from unsorted semen (Seidel, 2014). What is unknown from the current study is whether timing of ovulation

Table 5. Economic differences per pregnancy (cost per pregnancy of CON minus TAI, US\$) between CON and TAI according to observed and simulated inputs ${ }^{1}$

\begin{tabular}{|c|c|c|c|c|c|}
\hline \multirow[b]{2}{*}{ Scenario $^{2}$} & \multirow{2}{*}{$\begin{array}{l}\text { Study } \\
\mathrm{IR}^{3}\end{array}$} & \multicolumn{4}{|c|}{ Simulated $\mathrm{IR}^{4}$} \\
\hline & & $50 \%$ & $60 \%$ & $70 \%$ & $80 \%$ \\
\hline \multicolumn{6}{|c|}{ Feed, $\$ / \mathrm{kg}$ of DM } \\
\hline 0.15 & 11.35 & 10.51 & 8.06 & 6.04 & 4.33 \\
\hline 0.18 & 18.21 & 17.30 & 14.40 & 11.92 & 9.78 \\
\hline 0.21 & 25.07 & 24.15 & 20.68 & 17.73 & 15.22 \\
\hline \multicolumn{6}{|c|}{ Labor wage, $\$ / \mathrm{h}$} \\
\hline 8.00 & 11.71 & 10.71 & 8.00 & 5.71 & 3.77 \\
\hline 11.00 & 11.09 & 10.21 & 7.44 & 5.11 & 3.12 \\
\hline 14.00 & 10.48 & 9.71 & 6.88 & 4.50 & 2.48 \\
\hline \multicolumn{6}{|c|}{ Synchronization cost, $\$$} \\
\hline $10.00(1.67)$ & 17.99 & 17.30 & 14.46 & 12.06 & 10.01 \\
\hline $13.00(2.17)$ & 14.89 & 13.87 & 11.17 & 8.88 & 6.94 \\
\hline $16.00(2.67)$ & 11.79 & 10.45 & 7.87 & 5.70 & 3.87 \\
\hline \multicolumn{6}{|c|}{ Semen cost, $\$ /$ straw } \\
\hline 4.00 & 10.04 & 9.38 & 6.53 & 4.10 & 2.04 \\
\hline 7.00 & 11.93 & 10.87 & 8.18 & 5.91 & 3.99 \\
\hline 10.00 & 11.79 & 10.92 & 8.17 & 5.84 & 3.86 \\
\hline \multicolumn{6}{|c|}{$\mathrm{P} / \mathrm{AI}, \%$ of observed in study } \\
\hline 90 & 11.59 & 10.59 & 7.45 & 4.80 & 2.56 \\
\hline 80 & 11.95 & 10.86 & 7.25 & 4.21 & 1.63 \\
\hline 70 & 12.41 & 11.20 & 6.99 & 3.42 & 0.41 \\
\hline
\end{tabular}

${ }^{1} \mathrm{CON}=\mathrm{AI}$ after detected in spontaneous estrus or estrus induced by $\mathrm{PGF}_{2 \alpha}$ from d 0 to 84 of the study; TAI $=$ timed $\mathrm{AI}$ using the 5-d timed AI protocol for the first AI followed by detection of estrus for the remainder of the 84-d study. Values represent cost of a pregnancy in CON minus the cost of pregnancy in TAI.

${ }^{2}$ Distinct input scenarios were used for feed prices per kilogram of DM, labor wage cost per hour, synchronization treatments for TAI and $\mathrm{PGF}_{2 \alpha}$ used in $\mathrm{CON}$ (values in parentheses depict the cost of $\mathrm{PGF}_{2 \alpha}$ for $\mathrm{CON}$ ), semen value, and the relative pregnancy per $\mathrm{AI}(\mathrm{P} / \mathrm{AI})$ as percentage of those observed for each treatment in the study.

${ }^{3}$ Insemination rates (IR) were those observed in the study for each of the four 21 -d breeding periods according to treatment.

${ }^{4}$ Simulated values for IR were applied after the first 21-d breeding period and held constant for the 3 subsequent 21-d cycles. 
relative to AI was better synchronized in TAI than in CON heifers. Studies by our group have characterized the percentage of heifers ovulating to the first $\mathrm{GnRH}$ and luteal regression with a single or 2 treatments with $\mathrm{PGF}_{2 \alpha}$ in the 5-d timed AI protocol (Rabaglino et al., 2010; Lima et al., 2011, 2013). However, we are unaware of data on the exact timing of ovulation and the distribution of ovulations following the final $\mathrm{GnRH}$ treatment in the 5-d timed AI protocol. Usually, more than $70 \%$ of heifers display signs of estrus at timed AI (Lima et al., 2013), which was also observed in the current study. Ovulation typically occurs 26 to $28 \mathrm{~h}$ after the onset of estrus (Stevenson et al., 2014) or after the final injection of GnRH in the Ovsynch protocol (Pursley et al., 1995). Perhaps the administration of $\mathrm{GnRH}$ at $\mathrm{AI}$ reduced the variation in interval to ovulation in TAI compared with CON, which would help explain the improved P/AI when sex-sorted semen was used in TAI compared with CON heifers. Nevertheless, administration of GnRH concurrent with the initial detection of spontaneous estrus in dairy heifers and $12 \mathrm{~h}$ before AI did not improve P/AI (Sá Filho et al., 2010). It is also noteworthy that breeding programs based solely on detected estrus are subject to human error on identification of heifers manifesting estrous behavior, which could have contributed to the reduced $\mathrm{P} / \mathrm{AI}$ in $\mathrm{CON}$ heifers inseminated with sex-sorted semen. Perhaps, a combination of improved synchrony of ovulation with TAI and some lack of accuracy in detection of estrus explains the improved $\mathrm{P} / \mathrm{AI}$ in heifers receiving sexsorted semen for TAI compared with CON.

One of the objectives of the current study was to determine if implementation of timed AI would yield economic benefits by reducing the cost per pregnancy compared with heifers inseminated only after detected estrus. Heifer raising represents the second most important cost of producing milk in most farms, and feed is the major component affecting the cost of raising replacement heifers (Gabler et al., 2000; Mohd Nor et al., 2012). Proper reproductive management plays a key role in heifer raising because it determines when they become pregnant and, therefore, the cost associated with the reproductive program, and also the feed costs. In most farms, heifers are inseminated following detected estrus (NAHMS, 2009), likely because estrous expression is not thought to be an impediment for adequate reproduction. Previous studies with timed AI protocols resulted in $\mathrm{P} / \mathrm{AI}$ below $46 \%$ (Schmitt et al., 1996; Stevenson et al., 2000; Rivera et al., 2004, 2006), which likely discouraged producers from implementing Ovsynch or Cosynch in dairy heifers. Only $4 \%$ of the dairy farms in the United States evaluated in surveys in the last decade (NAHMS, 2009) reported that timed AI was the main method of insemination in dairy heifers. In many cases, farms use timed AI because of an inability to detect estrus or as a method to inseminate heifers not observed in estrus. However, the similar P/AI between TAI and CON in the present study observed in all 3 farms indicates that fixed-time insemination using the 5-d timed AI protocol should be considered as a method to manage reproduction in heifers, particularly for first insemination.

The economic analysis attempted to provide a comprehensive comparison of the 2 treatments to assess whether the benefits in reproductive performance obtained by incorporation of TAI would translate into reduced cost to obtain a pregnancy in dairy heifers. A previous simulation by Ribeiro et al. (2012) suggested that implementation of timed AI was an attractive and economical option for managing reproduction in dairy heifers, but the benefits were observed primarily when detection of estrus and insemination rate was less than $70 \%$. It is known that the economic benefits of timed AI are intensified when detection of estrus and insemination rate are low (Tenhagen et al., 2004). Interestingly, results from the current study demonstrated that implementing TAI for first AI resulted in a reduction in cost of $\$ 17.00$ per pregnancy with current market values for the inputs for hormonal treatments, semen, labor, pregnancy diagnosis, and feed costs. The less expensive pregnancy in TAI was observed in spite of the high detection of estrus and insemination rate observed for CON heifers $(82.4 \%)$. Therefore, even under situations in which the 21-d insemination rate is high, implementing TAI to inseminate all heifers as soon as they become eligible to be bred is attractive economically. The benefits observed with TAI included 8 fewer days to first AI and 12 fewer days to pregnancy, and TAI increased the daily rate of pregnancy by $60 \%$, which reduced the cost per pregnancy by $\$ 17.00$. The major component of the lesser cost per pregnancy in TAI was the marked reduction in feed cost. It is important to emphasize that not only was the cost per pregnancy reduced, but also more pregnant heifers were obtained within the 84-d breeding period, with the latter being an additional economic benefit of TAI.

Sensitivity analysis demonstrated that when feed cost was low and insemination rate after the first 21-d cycle was high, the economic benefit of TAI became negligible. The insemination rate for $\mathrm{CON}$ heifers after the first 21 -d cycle averaged $68.2 \%$. The reason for the decrease in insemination rate in CON heifers after the first 21-d cycle is that delayed insemination in the first $21 \mathrm{~d}$ of breeding will delay any subsequent insemination. After the first $\mathrm{AI}$, heifers can only receive $\mathrm{PGF}_{2 \alpha}$ to induce estrus once they are diagnosed as nonpregnant, 
which typically occurs at least $30 \mathrm{~d}$ after the previous insemination. Indeed, the 8-d-shorter interval to first AI was also observed for the second AI, which favored a greater detection of estrus because more nonpregnant TAI heifers than CON heifers returned to estrus within a given 21-d estrous cycle. In addition, before the first AI, 193 doses (0.64/heifer) of $\mathrm{PGF}_{2 \alpha}$ were administered to $\mathrm{CON}$ heifers, and use of $\mathrm{PGF}_{2 \alpha}$ is expected to improve insemination rate. Few reports in the literature have measured insemination rate continuously for dairy heifers. Studies usually report the percentage of heifers inseminated within the first $21 \mathrm{~d}$ after enrollment in a given treatment, which is usually high because of the ability to synchronize estrus with $\mathrm{PGF}_{2 \alpha}$. The results of insemination rate within the first $21 \mathrm{~d}$ for CON heifers are in line with those reported by others (Stevenson et al., 2008b). None of the farms in the study had insemination rates after the first $21 \mathrm{~d}$ of breeding above $70 \%$ for CON heifers, but if one could achieve $80 \%$ or greater, then the benefit of TAI would be diminished. When the costs associated with hormonal synchronization were high, then the economic benefit of TAI would be markedly reduced. In general, labor, semen plus insemination costs, and relative decreases in $\mathrm{P} / \mathrm{AI}$ had negligible effects on the economic differences between the 2 treatments. This negligible effect is explained by the similar fertility and similar labor required to implement either one of the breeding methods. Although most of the heifers were inseminated with conventional semen, a relative reduction in $\mathrm{P} / \mathrm{AI}$ to 80 or $70 \%$ of that observed in the current study still showed economic advantage of TAI over CON. This implies that even in situations when only sex-sorted semen is used, which typically reduces $\mathrm{P} / \mathrm{AI}$ to $80 \%$ of that observed with conventional semen (Seidel, 2014) or when fertility with conventional semen is low, the cost to generate a pregnancy would still be less for TAI than for CON.

\section{CONCLUSIONS}

Implementing timed AI using the 5-d timed AI protocol resulted in $\mathrm{P} / \mathrm{AI}$ that did not differ from that of CON heifers inseminated after detected estrus, but TAI improved $\mathrm{P} / \mathrm{AI}$ in heifers receiving sex-sorted semen, reduced days to first $\mathrm{AI}$, and increased insemination rate. The combination of improved insemination rate with similar $\mathrm{P} / \mathrm{AI}$ increased the daily rate of pregnancy by $60 \%$, resulting in a reduction of $12 \mathrm{~d}$ to pregnancy and increased proportion of pregnant heifers at the end of the 84-d study. The benefits of TAI were observed despite the relatively high insemination rate for CON heifers. The improved reproductive performance of TAI heifers resulted in a reduction in cost per pregnancy of
$\$ 17.00$, and this economic benefit was observed under different scenarios of hormonal synchronization, labor, semen, feed, and relative fertility.

\section{ACKNOWLEDGMENTS}

The authors thank the owners and staff of High Roller Dairy, John de Jong Dairy, and River Ranch Farms (all in Hanford, CA) for the use of their heifers and facilities. The assistance of César Narciso (Tulare, CA) is greatly appreciated. Our appreciation is extended to Richard W. Markham (Kansas City, KS) and Bayer HealthCare Animal Health (Whippany, NJ) for providing the OvaCyst and ProstaMate for this experiment.

\section{REFERENCES}

Cerri, R. L. A., H. M. Rutigliano, R. G. S. Bruno, and J. E. P. Santos. 2009. Progesterone concentration, follicular development and induction of cyclicity in dairy cows receiving intravaginal progesterone inserts. Anim. Reprod. Sci. 110:56-70.

Gabler, M. T., P. R. Tozer, and A. J. Heinrichs. 2000. Development of a cost analysis spreadsheet for calculating the costs to raise a replacement dairy heifer. J. Dairy Sci. 83:1104-1109.

Kuhn, M. T., J. L. Hutchison, and G. R. Wiggans. 2006. Characterization of Holstein heifer fertility in the United States. J. Dairy Sci. 89:4907-4920

Lima, F. S., H. Ayres, M. G. Favoreto, R. S. Bisinotto, L. F. Greco, E. S. Ribeiro, P. S. Baruselli, C. A. Risco, W. W. Thatcher, and J. E. P. Santos. 2011. Effects of gonadotropin-releasing hormone at initiation of the 5-d timed artificial insemination (AI) program and timing of induction of ovulation relative to AI on ovarian dynamics and fertility of dairy heifers. J. Dairy Sci. 94:4997-5004.

Lima, F. S., E. S. Ribeiro, R. S. Bisinotto, L. F. Greco, N. M. Martinez, M. Amstalden, W. W. Thatcher, and J. E. P. Santos. 2013. Hormonal manipulations in the 5-day timed artificial insemination protocol to optimize estrous cycle synchrony and fertility in dairy heifers. J. Dairy Sci. 96:7054-7065.

Machin, D., M. J. Campbell, P. M. Fayers, and A. P. Y. Pinol. 2008. Sample Size Tables for Clinical Studies. 3rd ed. Wiley, Hoboken, NJ.

Mohd Nor, N., W. Steeneveld, M. C. M. Mourits, and H. Hogeveen. 2012. Estimating the costs of rearing young dairy cattle in the Netherlands using a simulation model that accounts for uncertainty related to diseases. Prev. Vet. Med. 106:214-224.

NAHMS. 2009. Dairy 2007, Part IV: Reference of Dairy Cattle Health and Management Practices in the United States, 2007. \#N494.0209. Centers for Epidemiology and Animal Health, USDA: Animal and Plant Health Inspection Service: Veterinary Services, Fort Collins, CO.

NRC. 2001. Nutrient Requirements of Dairy Cattle. 7th rev. ed. Natl. Acad. Sci., Washington, DC.

Pursley, J. R., M. R. Kosorok, and M. C. Wiltbank. 1997a. Reproductive management of lactating dairy cows using synchronization of ovulation. J. Dairy Sci. 80:301-306.

Pursley, J. R., M. O. Mee, and M. C. Wiltbank. 1995. Synchronization of ovulation in dairy cows using $\mathrm{PGF}_{2 \alpha}$ and $\mathrm{GnRH}$. Theriogenology 44:915-923.

Pursley, J. R., M. C. Wiltbank, J. S. Stevenson, J. S. Ottobre, H. A. Garverick, and L. L. Anderson. 1997b. Pregnancy rates per artificial insemination for cows and heifers inseminated at a synchronized ovulation or synchronized estrus. J. Dairy Sci. 80:295-300.

Rabaglino, M. B., C. A. Risco, M.-J. Thatcher, I. H. Kim, J. E. P. Santos, and W. W. Thatcher. 2010. Application of one injection of prostaglandin $\mathrm{F}_{2 \alpha}$ in the five-day Co-Synch + CIDR protocol for 
estrous synchronization and resynchronization of dairy heifers. J. Dairy Sci. 93:1050-1058.

Ribeiro, E. S., K. N. Galvão, W. W. Thatcher, and J. E. P. Santos. 2012. Economic aspects of applying reproductive technologies to dairy herds. Anim. Reprod. 9:370-387.

Rivera, H., H. Lopez, and P. M. Fricke. 2004. Fertility of Holstein dairy heifers after synchronization of ovulation and timed AI after removed tail chalk. J. Dairy Sci. 87:2051-2061.

Rivera, H., R. A. Sterry, and P. M. Fricke. 2006. Presynchronization with gonadotropin-releasing hormone does not improve fertility in Holstein heifers. J. Dairy Sci. 89:3810-3816.

Sá Filho, M. F., H. Ayres, R. M. Ferreira, M. Nichi, M. Fosado, E. P. Campos Filho, and P. S. Baruselli. 2010. Strategies to improve pregnancy per insemination using sex-sorted semen in dairy heifers detected in estrus. Theriogenology 74:1636-1642.

Saacke, R. G. 2008. Insemination factors related to timed AI in cattle. Theriogenology 70:479-484.

Schmitt, E. J., P. T. Diaz, M. Drost, and W. W. Thatcher. 1996 Use of a gonadotropin-releasing hormone agonist or human chorionic gonadotropin for timed insemination in cattle. J. Anim. Sci. 74:1084-1091.

Seidel, G. E., Jr. 2014. Update on sexed semen technology in cattle. Animal 8(Suppl. 1):160-164.
Stevenson, J. L., J. C. Dalton, J. E. P. Santos, R. Sartori, A. Ahmadzadeh, and R. C. Chebel. 2008a. Effect of synchronization protocols on follicular development and estradiol and progesterone concentrations of dairy heifers. J. Dairy Sci. 91:3045-3056.

Stevenson, J. L., J. A. Rodrigues, F. A. Braga, S. Bitente, J. C. Dalton, J. E. P. Santos, and R. C. Chebel. 2008b. Effect of breeding protocols and reproductive tract score on reproductive performance of dairy heifers and economic outcome of breeding programs. J. Dairy Sci. 91:3424-3438.

Stevenson, J. S., S. L. Hill, R. L. Nebel, and J. M. DeJarnette. 2014. Ovulation timing and conception risk after automated activity monitoring in lactating dairy cows. J. Dairy Sci. 97:4296-4308.

Stevenson, J. S., J. F. Smith, and D. E. Hawkins. 2000. Reproductive outcomes for dairy heifers treated with combinations of prostaglandin F2alpha, norgestomet, and gonadotropin-releasing hormone. J. Dairy Sci. 83:2008-2015.

Tenhagen, B. A., M. Drillich, R. Surholt, and W. Heuwieser. 2004. Comparison of timed AI after synchronized ovulation to AI at estrus: Reproductive and economic considerations. J. Dairy Sci. 87:85-94. 